\title{
Einstieg in den CAD/CAM-Markt
}

Der globale Hersteller von dentalen Verbrauchsgütern Coltene wird neuer Materialpartner für das CAD/CAM-CEREC-System von Sirona. Unter dem Namen BRILLIANT Crios werden ab dem 1. Quartal 2016 die neuen „Reinforced Composite Blocs“ zur Chairside-Herstellung von defi-

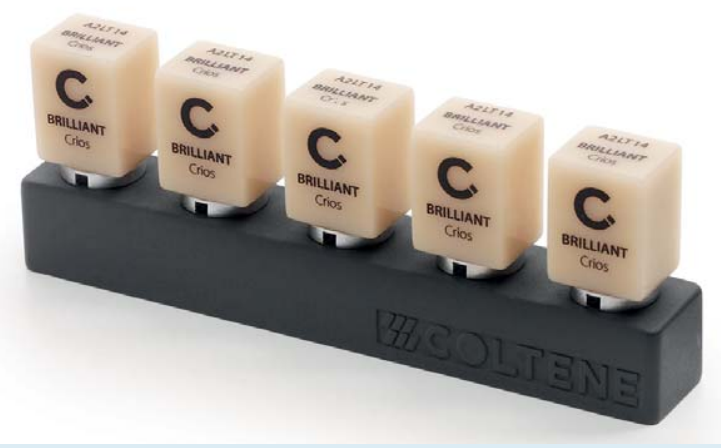

nitiven Inlays, Onlays, vollanatomischen Kronen und Veneers lanciert. Damit setzt Coltene gezielt auf den leistungsfähigen und vielseitigen Werkstoff Komposit und dessen computerunterstützte Verarbeitung direkt in der Zahnarztpraxis.

Jeffrey Slovin, CEO Sirona: „Coltene ist weltweit als traditioneller und vertrauenswürdiger Hersteller der Dentalindustrie bekannt. Wir freuen uns Coltene als offiziellen Verbrauchsmaterialanbieter für unser CEREC-System anlässlich des 30. Jahrestags von CEREC willkommen zu heißen. Die Erweiterung unserer Materialauswahl wird die
Nutzung der digitalen Zahnmedizin vergrößern, und natürlich einen enormen Vorteil für unsere CEREC-Kunden bedeuten. “ Martin Schaufelberger, CEO Coltene: „Coltene steht für Komposite. Als Pionier haben wir die Entwicklung der Komposite über Jahrzehnte maßgeblich vorangetrieben und geprägt. Heutzutage gibt es keinen Restaurationswerkstoff, dessen Eigenschaften so dicht an den natürlichen Zahn heranreichen wie Komposit.“

Vor diesem Hintergrund arbeiten die beiden Unternehmen künftig zusammen, um die gemeinsamen Potentiale der CAD/ CAM-Technologie und des Verbundwerkstoffs Komposit optimal auszuschöpfen.

Nach einer Pressemitteilung der Coltene Holding AG, CH - Altstätten www.coltene.com 